\title{
Cause Investigation of Volleyball Injury and Post-injury Treatment Strategies
}

\section{- An Investigation and Analysis of M School}

\author{
Pan $\operatorname{Yan}^{1, a}$ \\ ${ }^{1}$ Physical Education College, Hubei Normal University, HuangShi ,435002, China \\ a email:
}

Keywords: volleyball; sports injury; causes; post- injury treatment

\begin{abstract}
Like other sports, there is certain risk in volleyball. Once sport injuries occur, sport men will suffer mental and physical harm. Therefore, it has practical significance to research causes of volleyball injury and post-injury treatment. Based on the author's study and research experience for many years, this paper designs a questionnaire and selects students in M school to attend investigation, which summarizes typical causes of volleyball injury from the result obtained from the survey. Based on this, this paper proposes post-injury treatment countermeasures with hope to provide a reference for volleyball injury prevention and treatment in $\mathrm{M}$ school.
\end{abstract}

\section{Introduction}

With the continuous development and abundance of people's lives, volleyball has occupied a crucial position in the youth movement. Some schools even take volleyball as a teaching project to stimulate students' initiative to sports and improve the effectiveness of the student movement. It is easy to crash or fall in volleyball and sometimes it even causes muscle strain, joint dislocation, fractures, contusions and abrasions. We should make a full grasp in the movement and establish a system to conduct targeted injury treatment based on the above injuries so as to minimize the damage in volleyball.

\section{Research Object}

As one of sports with techniques and interest, Volleyball has become mainstream sport in physical exercise, especially in common required course in universities, which has received a very warm welcome. Although it contributes to students' health to some extent, it causes students' injuries with varying degrees some on account of students' lack of relevant skills and improper operation in volleyball. After the occurrence of the above sports injuries, many students do not know how to process it, which results in intensified damage affecting students' normal life. To solve the above problems and to ensure that students can correctly handle volleyball injuries and avoid them, the paper investigates causes of volleyball injuries and makes a deep analysis of treatment measures in order to provide some references to injury control[1].

\section{Research Method and Content}

Research object. As our country's high education institutions, $M$ school attaches great 
importance to the physical education of students, and it forms a very systematic teaching content on the basis of the requirements of physical education, including football, basketball, volleyball and so on, which provides students with a wide range of public physical education selection space. In the process of this study, the author mainly selects the students who are often involved in Volleyball between 18 20 years of age as the object of investigation. The investigation process selects 300 students, including 214 boys and 86 girls. We distributed a total of 300 questionnaires, 255 valid questionnaires were recovered, accounting for $85.0 \%$ of the total.

Research methods. After analyzing the age level of volleyball players, We found that the freshman and the sophomore are the main players in volleyball, therefore, in the course of the investigation, we investigate the age level of 18 20 years old. Through interview method to interview the teachers and volleyball staff engaged in the teaching of volleyball for many years, getting to understand the cause of volleyball sports injury, and by listening to their experiences and suggestions, we can sum up the injury treatment measures of volleyball sports injuries.

Statistical processing. By statistics software, this paper deals with the data, researches the data in the law and then determines the M school students volleyball sports injury situation.

\section{Research Results}

Investigation on the damage of volleyball. Types of the sport injury. In the course of this investigation, there are 255 students appearing in different degrees of volleyball sports injury in the process of movement, including fracture, dislocation, contusion, strain,sprain, bruise, etc. Among them, the strain accounts the most, a total of 326 times, accounting for $61.4 \%$ of the total. See Table 1.

Table 1 the main types of student volleyball sport injury

\begin{tabular}{ccccccccc}
\hline type & fracture & $\begin{array}{c}\text { dislocation of } \\
\text { joint }\end{array}$ & contusion & strain & sprain & scratch & other & total \\
\hline frequency & 5 & 6 & 16 & 326 & 48 & 85 & 45 & 531 \\
$\%$ & 1.0 & 1.3 & 3 & 61.4 & 9 & 16 & 8.3 & 100 \\
\hline
\end{tabular}

From view of this, the students in the process of volleyball are prone to strain, bruise and strain, in generally, these sports injuries are relatively light and the post injury treatment is relatively simple, so it generally will not cause too much impact on students. But in the course of the interview, we also found that the above the injuries is mainly due to they do not pay attention to the movement process. Once the students have sports injuries knowledge, the possibility of a sharp will decrease in the incidence of injury, which needs to pay attention to the future of volleyball education in the process of education.

The degree of sport injury. In the course of the injury degree of volleyball, we divided it into mild injury, moderate injury and severe injury, and its specific indicators are shown in Table 2.

Table 2 damage index of volleyball

\begin{tabular}{|c|c|}
\hline type & index \\
\hline mild injury & $\begin{array}{l}\text { Although injured but does not affect the normal working and life. Such } \\
\text { as minor scratches, strain, bruise, strain and so on. }\end{array}$ \\
\hline moderate injury & $\begin{array}{l}\text { The injured parts can not be normal activities, and needs to minimize } \\
\text { activities. Such as some serious scratches, strain, strain, contusion and } \\
\text { so on. }\end{array}$ \\
\hline severe injury & $\begin{array}{l}\text { Injury degree is relatively serious. The injured should be in bed rest and } \\
\text { receive treatment, such as fracture, dislocation of the joint. }\end{array}$ \\
\hline
\end{tabular}

The study found that the injuries of volleyball are mainly mild injuries and they can be 
normal movement, after seven days, there is no big obstacle. Severe injuries occurred 11 times, accounting for the overall $2.3 \%$. In the process of interview with students with severe injuries, we found that the main factors that cause serious injury of student volleyball are the improper operation and the unsuitable sports environment in the process of movement, which has a very big relationship with the outside world, Therefore, in the process of volleyball sport in the future, it needs to conduct a comprehensive analysis to avoid the occurrence of injury.

Sports injury site. The survey found that the main parts of students volleyball injury are the hand, foot, elbow, and the hand is the most, a total of 3212 times, accounting for $40 \%$ of the total. See Table 3.

Table 3 the position of Students volleyball

\begin{tabular}{ccccccccccc}
\hline position & shoulder & neck & hand & $\begin{array}{c}\text { waist } \\
\text { hip }\end{array}$ & foot & thigh & leg & elbow & other & total \\
\hline frequency & 48 & 9 & 212 & 22 & 97 & 10 & 9 & 65 & 59 & 531 \\
$\%$ & 9 & 1.7 & 40 & 4.1 & 18.2 & 2 & 1.7 & 12.3 & 11 & 100 \\
\hline
\end{tabular}

From the data in the table we can find: In the course of volleyball sports injury, it needs to protect the department of foot and elbow. Combining with the above data, it is necessary to enhance the importance of the above mentioned data to reduce the damage of the mentioned parts.

Damage cause investigation of the volleyball sport. From the survey data we found: Firstly, the technical operation is not standardized that causes many injuries, a total of 179 times, accounting for $28.6 \%$ of the total; Secondly, the improper use of protective gear, there were 137 times, accounting for $25.6 \%$ of the total; Thirdly, for emergencies, a total of 39 times, accounting for $8.3 \%$ of the total. See Table 4 .

Table 4 causes of volleyball sports injuries

\begin{tabular}{cccc}
\hline injury causes & number of injuries & percentage & Number of injuries / average \\
\hline $\begin{array}{c}\text { site, equipment is not } \\
\text { reasonable }\end{array}$ & 18 & $9.4 \%$ & 30 \\
$\begin{array}{c}\text { the improper use of protective } \\
\text { clothing }\end{array}$ & 49 & $25.6 \%$ & 137 \\
inadequate preparation & 11 & $5.7 \%$ & 17 \\
activities & 55 & $28.6 \%$ & 179 \\
operation is not standardized & 16 & $8.3 \%$ & 39 \\
emergent events & 43 & $22.4 \%$ & 129 \\
other reasons & 192 & $100 \%$ & 531 \\
\hline total & & & \\
\hline
\end{tabular}

Survey shows that many students are due to the operation is not standardized, so that it leads to sports injury, and it mainly includes the way of hitting the ball is not correct in the volleyball movement, or the volleyball strength is too big. In the course of volleyball, the students pursuit of strength and the effect of hitting the ball, so they often challenge the action of high difficulty, in this process, it's easy to have technical mistakes, causing fingers to damage or fall down, which greatly increases the risk of students volleyball sports injury[2]. The improper use of protective clothing is also a common cause of injury in volleyball and it mainly occurs in the early stage of students' volleyball. In the early learning the course of volleyball, it is easy to appear the volleyball injury due to unreasonable use of protective gear. At the same time, after a long time, some students my despise protector, and some even do not wear protective clothing, which causes the student damage risk to rise sharply, and it has seriously affected the health and the security. Apart from the main factors, the factors leading to the injury of student volleyball sport salso include venues, equipment 
factors, emergencies, inadequate preparation activities, etc. M school often directly carries out volleyball in the land, rather than the plastic ground, which to a certain extent, will increase the risk of volleyball sports injuries[3].

\section{Discussion}

Volleyball needs more long-term endurance, and it can comprehensively improve people's physical quality and physical function in the process of aerobic exercise. The movement has a very wide range of mass, and the technical requirements are more stringent, needing to continue to hit the ball in the process of movement, which not only needs to ensure the accuracy and effectiveness of the attack technology, but also to ensure the endurance of the ball. Volleyball sports requirements are very high on the collective, in the process of movement, it is very easy to appear damage. Therefore, in the process of volleyball, we must to pay more attention to the injury, by analyzing the cause of volleyball injury, to implement the preventive control and post injury treatment, in order to minimize the damage to people's physical health, and to ensure the safety of volleyball sport.

Hand injury is the most frequent occurrence of injury in volleyball, this is mainly due to, in the process of hitting the ball, if the force is too large or the way of volleyball is not correct, it is easy to cause damage to the fingers, hands or wrists, if severe, it even leads to injury to the arm or shoulder joint, all those injuries have a very serious impact on the health of the students. Meanwhile, in the process of ball biting, it also needs the help of the strength of the waist, through the waist muscle movement to ensure the balance of body and movement, so as to realize the ball biting. In the process, when the waist is not in harmony with the body's actions, it is easy to cause lumbar strain[4]. In addition, in order to keep the balance and movement, knee, leg and foot movements are also crucial, which is the volleyball base of the ready posture, movement, passing, passing, serving, spiking, blocking. In the ordinary course of volleyball, it mainly through the cross slide, step, hop, step and running to achieve volleyball, in this process, it is easy to collide, scratch, etc., resulting in joint dislocation, scratch, strain, etc.. For this, the school must do a good job in the prevention and control of students volleyball sport injury, in combination with the students' volleyball sports injury situation to reduce the damage of volleyball and ensure the safety of the students.

The investigation and study found that student volleyball sport injuries include fracture, dislocation, injury, strain, strain, bruise, and so on, among them, the strain is the most common, and the scratch is the second; The main damage site is hand, foot, elbow, among them, the hand is the most common, and the foot is the second; Sports injury degree is generally mild, and they are caused by the improper use of equipment space, unreasonable protective gear, insufficient preparation, unexpected events, which is consistent with the results of literature analysis.

\section{References}

[1] Chen Lijuan, Ma Si-ji. Investigation and Analysis on the sports injuries of middle school students in Shanxi [J]. Shanghai sports science and technology, 2012,02:56-59.

[2] Zhang Guosheng. Research on the common sports injury in University Students Volleyball in Zhengzhou [J]. Journal of Mudanjiang Normal College (NATURAL SCIENCE EDITION), 2012,04:41-42.

[3] Ma Lixin. College Students Volleyball Sports Injury Investigation and analysis -- Taking the eastern colleges and universities in Inner Mongolia Autonomous Region for cases [J]. Baotou Vocational \& Technical College. 2014,01:80-81+84. 
[4] Ma Cailan. Sports injury and prevention of volleyball athletes in Colleges and universities [J]. Journal of Jiangsu Institute of Economic\&Trade Technology, 2014,03:57-59.

(不加备注) 地址: 石家庄元氏县文化路与昌盛街交叉口东行 100 米路北梓墨文化 18630132561 张琼 
